\title{
Comment on the Article "Simple Maneuver to Tide Over the Crisis Due to Intraoperative Malfunctioning of a Pilot Balloon"
}

\author{
Summit D. Bloria ${ }^{1}$ Ankur Luthra ${ }^{1}$ Pallavi Bloria ${ }^{2}$ \\ ${ }^{1}$ Department of Anaesthesia, Postgraduate Institute of Medical \\ Education and Research, Chandigarh, India \\ 2Department of Anesthesia, Government Medical College, \\ Jammu, India
}

J Neuroanaesthesiol Crit Care 2019;6:51

We read the article by Dhanda et $\mathrm{al}^{1}$ and would like to congratulate the authors for management of an unforeseen complication intraoperatively. However, we would like to submit that the authors' contention of this being a modified/ novel technique is misplaced.

Inserting an intravenous cannula sheath into a severed inflation line of an endotracheal tube/tracheostomy tube and then attaching a three-way distal to it has been described previously on many occasions. Watson et al had described the same technique back in $1989 .{ }^{2}$

Gupta et al make a mention of this precise method in their article in 2010. ${ }^{3}$ Also, Rao et al in an article in 2014 have described precisely the same technique. ${ }^{4}$

We believe that authors demonstrated a novel application (in a prone patient) of an already described technique rather than demonstrating a novel technique. That being said, they must be commended for their presence of mind and for reminding the readers of a simple method to "tide over" a potentially dangerous intraoperative situation.

\section{Funding}

None.

\section{Conflict of Interest \\ None declared.}

\section{Note}

The authors submit that they are satisfied with the response and clarifications given by the authors of the said article and thank them for replying to the questions raised by us.

\section{References}

1 Dhanda A, Dube SK, Agarwal S, Satyarthee GD. Simple maneuver to tide over the crisis due to intraoperative malfunctioning of a pilot balloon. J Neuroanaesthesiol Crit Care 2018;5(3):204-205

2 Watson E, Harris MM. Leaking endotracheal tube. Chest 1989;95(3):709

3 Gupta B, Farooque K, Jain D, Kapoor R. Improper tube fixation causing a leaky cuff. J Emerg Trauma Shock 2010;3(2):182-184

4 Rao AK, Chaudhuri S, Joseph TT, Kamble D, Gotur G, Venkatesh S. Severed cuff inflation tubing of endotracheal tube: a novel way to prevent cuff deflation. Anesth Essays Res 2014;8(2):243-246
Address for correspondence Summit D. Bloria, MD, DNB, Department of Anesthesia, Postgraduate Institute of Medical Education and Research, Chandigarh, India

(e-mail: summitbloria13@gmail.com).
DOI https://doi.org/ $10.1055 / \mathrm{s}-0038-1677640$ ISSN 2348-0548.
Copyright $\odot 2019$ Indian Society of Neuroanaesthesiology and Critical Care
License terms

() (1) $\Theta \circledast$ 